\title{
CPT-TODIM METHOD FOR INTERVAL-VALUED BIPOLAR FUZZY MULTIPLE ATTRIBUTE GROUP DECISION MAKING AND APPLICATION TO INDUSTRIAL CONTROL SECURITY SERVICE PROVIDER SELECTION
}

\author{
Mengwei $\mathrm{ZHAO}^{1}$, Guiwu $\mathrm{WEI}^{1}$, Yanfeng $\mathrm{GUO}^{2}$, Xudong $\mathrm{CHEN}^{3 *}$ \\ ${ }^{1}$ School of Business, Sichuan Normal University, 610101 Chengdu, P.R. China \\ ${ }^{2}$ School of Finance, Southwestern University of Finance and Economics, 610074 Chengdu, P.R. China \\ ${ }^{3}$ School of Accounting, Southwestern University of Finance and Economics, 611130 Chengdu, P.R. China
}

Received 17 November 2020; accepted 28 February 2021; first published online 05 July 2021

\begin{abstract}
In recent years, a series of serious attacks against industrial control system (ICS), such as Stuxnet, Duqu, Flame and Havex, have sounded the alarm for industrial enterprises. For many industrial enterprises, it is a very important part of enterprise management decisions to evaluate ICS security suppliers and choose the appropriate one as a partner. The purpose of this paper is to build the TODIM method based on cumulative prospect theory (CPT-TODIM) to solve multiattribute group decision making problem under interval-valued bipolar fuzzy environment. This extraordinary model not only uses CPT to supplement the traditional TODIM method, but also introduces the entropy weight method to determine the attribute weight so as to avoid the negative influence of subjective weight on the decision result. In addition, in this model, all attribute evaluation information will be interval-valued bipolar fuzzy number (IVBFN) to cope with complex and fuzzy decision environment. Then, the most important part of this paper, we elaborate on the logical structure of the model. What's more, in the last two sections, we apply this newly constructed model to the selection of ICS security suppliers, and verify the acceptability of this method by sensitivity analysis and comparing with IVBFWA and IVBFWG operator.
\end{abstract}

Keywords: multi-attribute group decision making (MAGDM), interval-valued bipolar fuzzy sets, TODIM, CPT, industrial control security, service provider selection.

JEL Classification: C43, C61, D81.

\section{Introduction}

With the development of next-generation information technologies, many countries have proposed strategies to accelerate the integration of information technology and manufacturing technologies, such as Germany's industry 4.0 strategy, the reindustrialization in the

This article was originally published with error. This version has been amended. Please see Corrigendum https://doi.org/10.3846/tede.2022.16479

*Corresponding author. E-mail: xutung99@126.com

Copyright (c) 2021 The Author(s). Published by Vilnius Gediminas Technical University

This is an Open Access article distributed under the terms of the Creative Commons Attribution License (http://creativecommons. org/licenses/by/4.0/), which permits unrestricted use, distribution, and reproduction in any medium, provided the original author and source are credited. 
United States, and the "Made in China 2025" plan. All of these have prompted the further development of industrial control system (ICS). While infusing new development vigor into ICS, information technology also brings new security hidden danger. Industrial control system, as the brain and central nerve of important national infrastructure, is concerned with national economy and people's livelihood. In addition, in recent years, a series of serious attacks against ICS, such as Stuxnet, Duqu, Flame and Havex, have sounded the alarm for the authority and industrial enterprises. Hence, how to ensure the security of an increasingly open ICS is a grim problem facing by many industrial enterprises. And it is a very important part of management decisions to evaluate ICS security suppliers and choose the appropriate one. The choice of ICS security supplier is a typical multi-attribute decision making (MADM) problem (Wang et al., 2021).

At present, scientists have created a lot of methods to solve the problem of MADM, such as the TODIM method (Gomes \& Rangel, 2009), MABAC method (Pamucar \& Cirovic, 2015), EDAS method (Keshavarz Ghorabaee et al., 2015), VIKOR method (Opricovic \& Tzeng, 2004), GRA method (Wei et al., 2020), CODAS method (Keshavarz Ghorabaee et al., 2016), GLDS method (Wu \& Liao, 2019), CoCoSo method (Yazdani et al., 2018), QUALIFLEX method (Paelinck, 1978), etc. However, with the continuous improvement of technology, researchers have found that the decision-making environment is more complex, and ambiguity and uncertainty is higher as well. Only using traditional methods to solve MADM problems can't meet the practical requirements (He et al., 2020a). Therefore, many scholars begin to deal with MADM issues by combining fuzzy numbers with traditional MADM methods (He et al., 2020b). The concept of fuzzy set was first proposed by Zadeh (1965). Its characteristic is to describe the thing between "absolutely yes" and "absolutely not" with the membership degree. Since then, the notion of fuzzy set (FS) has been constantly developed and expanded. Atanassov (1986) proposes intuitionistic fuzzy set (IFS) and further proposes interval-valued intuitionistic fuzzy set (IVIFS). Xiao et al. (2020) defined the intuitionistic fuzzy Taxonomy method. Both IFS and IVIFS use membership degree, non-membership degree and hesitancy degree to describe the recognition degree of an object to a certain property. However bipolar fuzzy set (BFS) proposed by Zhang (1996) in 1994 broke this above phenomenon. BFS makes use of positive and negative membership degrees to describe the recognition degree of an object to a certain property and the recognition degree of this object to opposite property respectively. Different from other fuzzy sets, BFS has attracted the attention of many scholars and has important applications in many fields. Jana et al. (2020) investigated Dombi and sought for a better combination of Dombi and BFN. Eventually, they determined adding prioritized aggregation operators to the old ones. Akram et al. (2020) considered a combination of TOPSIS and ELECTRE-I in the BF environment. In view of the fact that individual values still disturb decision makers when they express their views, interval numbers are more helpful for decision makers. Therefore, just as other fuzzy sets extend to interval fuzzy sets, BFS is also extended to the domain of interval numbers. Wei et al. (2018) put forward the concept of interval-valued bipolar fuzzy set (IVBFS), and put forward a lot of operators for interval-valued bipolar fuzzy number (IVBFN), such as: the internal-valued bipolar fuzzy weighted averaging (IVBFWA) operator, the internal-valued bipolar fuzzy weighted geometric (IVBFWG) operator. Tehrim and Riaz (2020) put forward a novel VIKOR method based on IVBFN and the set pair analysis (SPA) theory. However, there are few researches on IVBFS for MADM. Therefore, the MADM under IVBF is worthy of attention. 
TODIM method has advantages in depicting decision-maker's psychological state. There have been many researches on the MADM in fuzzy environment. In order to solve the evaluation of service quality, Mishra et al. (2020) advanced IVIF-TODIM method in accordance with entropy and divergence measures. The shadowed set which was utilized by He et al. (2021) for building up the traditional TODIM method is a new assessment tool for fuzzy information. Ashofteh et al. (2020) realized a good application of TODIM method in water resources. Guo et al. (2020) found out mixed TODIM method which is capable of settling the site choice of Carbon storage. According to the characteristics of TODIM method and PROMETHEE method, Xu et al. (2020) combined them skillfully and successfully applied them to the single-valued neutrosophic environment. This pattern of combining the TODIM method with another approach seems to have been a recent trend among researchers. Arya and Kumar (2020a) implemented the combination of VIKOR and TODIM method under picture fuzzy set, and introduced Shannon entropy. Moreover, Arya and Kumar (2020b) also took advantage of divergence measures to enrich this combination.

Tian et al. (2019) introduced cumulative prospect theory (CPT) into TODIM method for the first time, which made TODIM method more complete in expressing the influence of decision-maker's psychological state on decision making. Zhao et al. (2021a) defined the CPT-TODIM method for intuitionistic fuzzy MAGDM. Zhao et al. (2021b) proposed the CPT-TODIM method for interval-valued intuitionistic fuzzy MAGDM. Tian et al. (2020) believed that TODIM method failed to form a high degree of consistency with prospect theory (PT), and advocated to use probabilistic hesitation fuzzy information to build a more complete TODIM method. Tian et al. (2021) imparted a new TODIM model with q-rung qrthopair fuzzy set to dispose the choice of green supplier. Zhao et al. (2021c) defined the CPT-TODIM method with 2-tuple linguistic neutrosophic sets. Lu et al. (2020) designed the Pythagorean 2-tuple linguistic CPT-TODIM method. In a decision analysis, in addition to the fuzziness and uncertainty of the decision object, the decision maker is also one of the important factors affecting the final result. It is necessary to give full consideration about the psychology of decision makers. Furthermore, the description of decision-maker's psychology is conducive to improve the reality and credibility of decision-making results. On the one hand, the conception of introducing CPT into TODIM can make the original TODIM method more complete and further highlight the advantages of TODIM method. On the other hand, there is a disappointing phenomenon that researches about IVBFN and TODIM method as the foundation to establish MAGDM model rarely happened. Hence, a new TODIM method on the basis of CPT (CPT-TODIM method) and IVBFN information is constructed in this article with the purpose of imparting an extraordinary approach for multi-attribute group decision making (MAGDM) problem. In brief, three innovations in this paper are mentioned. Firstly, the proposed model not only uses CPT to supplement the traditional TODIM method, but also introduces the entropy weight method (Liu et al., 2020) to determine the attribute weight. Entropy (Shannon, 1948) is regarded as a measure of the disorder of a system. The smaller value of information entropy denotes a greater dispersion degree of an index. The entropy weight method epitomized the general conception that the index whose dispersion degree is higher is endowed with a greater weight in determining objective weight. Moreover, compared with other methods, the entropy weight method is 
simple and easy to understand, and has stronger operability. Therefore, the entropy weight method is an effective way to improve the precision of sequence. Secondly, in this model, all attribute evaluation information will be IVBFN to cope with complex and fuzzy decision environment. In addition, the model is put into use in the selection of industrial control system security suppliers.

The specific writing framework of this paper is as follows. In Section 1, we focus on the knowledge related to IVBF. In the second part, we propose the CPT-TODIM method under IVBF on the basis of reviewing the general CPT-TODIM method. In Section 3, we study the safety of ICS and take advantage of this new model to help industrial enterprises choose the appropriate ICS security supplier. At the end of this paper, the availability of the new model is proved by comparing with the results of two operators (IVBFWA and IVBFWG).

\section{Preliminary knowledge}

In this section, we provide the conceptions of BFS as well as IVBFS, and the mathematical operations of interval-valued bipolar fuzzy number (IVBFN), such as, evaluation function, operational rules and aggregation operators.

\subsection{BFS and IVBFS}

Bipolar fuzzy set (BFS) proposed by Zhang (1996) in 1994 makes use of positive and negative membership degrees to describe an object from the certain property and the opposite property respectively.

Definition 1 (Zhang, 1996). Assume there is a non-empty set $E$, we are capable to define a BFS by utilizing the Eq. (1):

$$
q=\left\{\left\langle e,\left(P_{q}^{+}(e), N_{q}^{-}(e)\right)\right\rangle \mid e \in E\right\}
$$

where $P_{q}^{+}(e)$ as well as $N_{q}^{-}(e)$ respectively represent the degree to which an element $e$ is a member of the corresponding property and its opposite-property. In addition, $0 \leq P_{q}^{+}(e) \leq 1$ and $-1 \leq N_{q}^{-}(e) \leq 0$, which means $-1 \leq P_{q}^{+}(e)+N_{q}^{-}(e) \leq 1$.

Because interval fuzzy numbers can eliminate some confusion of decision makers, Wei et al. (2018) put forward the concept of interval-valued bipolar fuzzy set (IVBFS).

Definition 2 (Wei et al., 2018). Assume there is a non-empty set $E$, we are capable to define a IVBFS by utilizing the Eq. (2):

$$
\tilde{q}=\left\{\left\langle e,\left(\tilde{P}_{\tilde{q}}^{+}(e), \tilde{N}_{\tilde{q}}^{-}(e)\right)\right\rangle \mid e \in E\right\}=\left\{\left\langle e,\left(\left[\tilde{P}_{\tilde{q}}^{L+}(e), \tilde{P}_{\tilde{q}}^{U+}(e)\right],\left[\tilde{N}_{\tilde{q}}^{L-}(e), \tilde{N}_{\tilde{q}}^{U-}(e)\right]\right)\right\rangle \mid e \in E\right\}
$$

where $\tilde{P}_{\tilde{q}}^{+}(e) \subset[0,1]$ as well as $\tilde{N}_{\tilde{q}}(e) \subset[-1,0]$ respectively represent the degree to which an element $e$ is a member of the corresponding property and its opposite-property.

Referring to the above definition of IVBFS, IVBFN is expressed as $\tilde{\tilde{q}}=\left(\tilde{P}_{\tilde{\tilde{q}}}^{+}, \tilde{\tilde{\tilde{q}}} \overline{\tilde{q}}\right)=$ $\left(\left[\tilde{P}_{\tilde{q}}^{L+}, \tilde{P}_{\tilde{q}}^{U+}\right],\left[\tilde{N}_{\tilde{q}}^{L-}, \tilde{N}_{\tilde{q}}^{U-}\right]\right)$. 
Definition 3 (Wei et al., 2018). The concepts of score function $S F(\tilde{\tilde{q}})$ and accuracy function $A F(\tilde{\tilde{q}})$ for $\tilde{\tilde{q}}=\left(\tilde{P}_{\tilde{\tilde{q}}}^{+}, \tilde{N}_{\tilde{\tilde{q}}} \overline{)}\right)=\left(\left[\tilde{P}_{\tilde{\tilde{q}}}^{L+}, \tilde{P}_{\tilde{q}}^{U+}\right],\left[\tilde{N}_{\tilde{\tilde{q}}}^{L-}, \tilde{N}_{\tilde{\tilde{q}}}^{U-}\right]\right)$ are derived as Eq. (3) as well as (4) in order to determine the relative relationship between two IVBFNs.

$$
\begin{gathered}
S F(\tilde{\tilde{q}})=\frac{\left(1+\tilde{P}_{\tilde{\tilde{q}}}^{L+}+\tilde{N}_{\tilde{\tilde{q}}}^{L-}\right)+\left(1+\tilde{P}_{\tilde{\tilde{q}}}^{U+}+\tilde{N}_{\tilde{\tilde{q}}}^{U-}\right)}{4}, \quad S F(\tilde{\tilde{q}}) \in[0,1] ; \\
A F(\tilde{\tilde{q}})=\frac{\left(\tilde{P}_{\tilde{\tilde{q}}}^{L+}-\tilde{N}_{\tilde{\tilde{q}}}^{L-}\right)+\left(\tilde{P}_{\tilde{\tilde{q}}}^{U+}-\tilde{N}_{\tilde{\tilde{q}}}^{U-}\right)}{4}, \quad A F(\tilde{\tilde{q}}) \in[0,1] .
\end{gathered}
$$

Definition 4 (Wei et al., 2018). Suppose two IVBFNs $\tilde{\tilde{q}}_{1}=\left(\tilde{P}_{\tilde{\tilde{q}}_{1}^{+}}^{+}, \tilde{N}_{\tilde{\tilde{q}}_{1}}\right)=\left(\left[\tilde{P}_{\tilde{q}_{1}}^{L+}, \tilde{P}_{\tilde{\tilde{q}}_{1}}^{U+}\right]\right.$, $\left.\left[\tilde{N}_{\tilde{\tilde{q}}_{1}}^{L-}, \tilde{N}_{\tilde{\tilde{q}}_{1}}^{U-}\right]\right)$ and $\tilde{\tilde{q}}_{2}=\left(\tilde{P}_{\tilde{\tilde{q}}_{2}}^{+}, \tilde{N}_{\tilde{\tilde{q}}_{2}}\right)=\left(\left[\tilde{P}_{\tilde{\tilde{q}}_{2}}^{L+}, \tilde{P}_{\tilde{\tilde{q}}_{2}}^{U+}\right],\left[\tilde{N}_{\tilde{\tilde{q}}_{2}}^{L-}, \tilde{N}_{\tilde{\tilde{q}}_{2}}^{U-}\right]\right):(1)$. If $\operatorname{SF}\left(\tilde{\tilde{q}}_{1}\right)>\operatorname{SF}\left(\tilde{\tilde{q}}_{2}\right)$, then $\tilde{\tilde{q}}_{1}>\tilde{\tilde{q}}_{2}$; (2) If $\operatorname{SF}\left(\tilde{\tilde{q}}_{1}\right)=\operatorname{SF}\left(\tilde{\tilde{q}}_{2}\right)$, then there is a requirement to compare accuracy functions: $A F\left(\tilde{\tilde{q}}_{1}\right)>A F\left(\tilde{\tilde{q}}_{2}\right)$ means $\tilde{\tilde{q}}_{1}>\tilde{\tilde{q}}_{2} ; A F\left(\tilde{\tilde{q}}_{1}\right)=A F\left(\tilde{\tilde{q}}_{2}\right)$ means $\tilde{\tilde{q}}_{1}=\tilde{\tilde{q}}_{2}$.

Definition 5 (Wei et al., 2018). Give three IVBFNs $\tilde{\tilde{q}}=\left(\tilde{P}_{\tilde{q}}^{+}, \tilde{N}_{\tilde{\tilde{q}}} \overline{ }\right)=\left(\left[\tilde{P}_{\tilde{q}}^{L+}, \tilde{P}_{\tilde{q}}^{U+}\right],\left[\tilde{N}_{\tilde{q}}^{L-}, \tilde{N}_{\tilde{q}}^{U-}\right]\right)$, $\tilde{\tilde{q}}_{1}=\left(\tilde{P}_{\tilde{\tilde{q}}_{1}^{+}}^{+}, \tilde{N}_{\tilde{\tilde{q}}_{1}}^{\bar{q}_{1}}\right)=\left(\left[\tilde{P}_{\tilde{\tilde{q}}_{1}}^{L+}, \tilde{P}_{\tilde{\tilde{q}}_{1}}^{U+}\right],\left[\tilde{N}_{\tilde{\tilde{q}}_{1}}^{L-}, \tilde{N}_{\tilde{\tilde{q}}_{1}}^{U-}\right]\right)$ and $\tilde{\tilde{q}}_{2}=\left(\tilde{P}_{\tilde{\tilde{q}}_{2}}^{+}, \tilde{N}_{\tilde{\tilde{q}}_{2}}\right)=\left(\left[\tilde{P}_{\tilde{\tilde{q}}_{2}}^{L+}, \tilde{P}_{\tilde{\tilde{q}}_{2}}^{U+}\right],\left[\tilde{N}_{\tilde{\tilde{q}}_{2}}^{L-}, \tilde{N}_{\tilde{\tilde{q}}_{2}}^{U-}\right]\right)$, and the basic operations of them are shown in the following:
(1) $(\tilde{\tilde{q}})^{c}=\left(\left[1-\tilde{P}_{\tilde{\tilde{q}}}^{U+}, 1-\tilde{P}_{\tilde{q}}^{L+}\right],\left[\left|\tilde{N}_{\tilde{q}}^{U-}\right|-1,\left|\tilde{N}_{\tilde{\tilde{q}}}^{L-}\right|-1\right]\right)$;

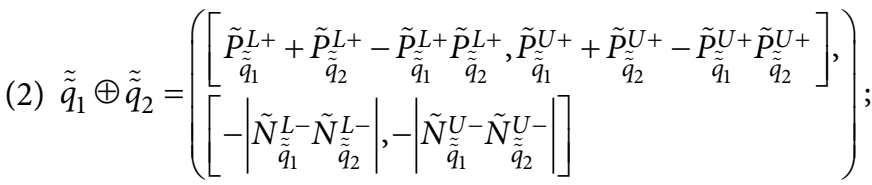

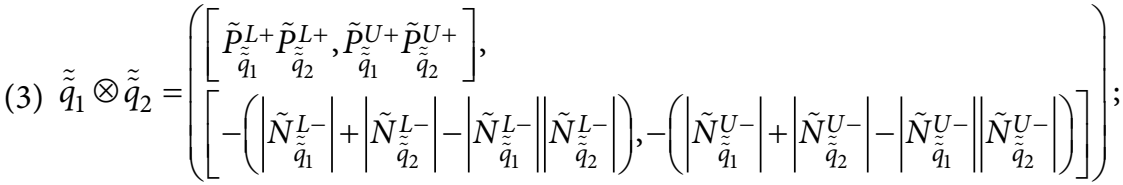
(4) $\delta \tilde{\tilde{q}}=\left(\left[1-\left(1-\tilde{P}_{\tilde{\tilde{q}}}^{L+}\right)^{\delta}, 1-\left(1-\tilde{P}_{\tilde{\tilde{q}}}^{U+}\right)^{\delta}\right],\left[-\left|\tilde{N}_{\tilde{\tilde{q}}}^{U-}\right|^{\delta},-\left|\tilde{N}_{\tilde{\tilde{q}}}^{L-}\right|^{\delta}\right]\right), \delta>0$;
(5) $\tilde{\tilde{q}}^{\delta}=\left(\left[\left(\tilde{P}_{\tilde{\tilde{q}}}^{L+}\right)^{\delta},\left(\tilde{P}_{\tilde{\tilde{q}}}^{U+}\right)^{\delta}\right],\left[-1+\left|1+\tilde{N}_{\tilde{\tilde{q}}}^{L-}\right|^{\delta},-1+\left|1+\tilde{N}_{\tilde{\tilde{q}}}^{U-}\right|^{\delta}\right]\right), \delta>0$;

Definition 6. The Eq. (5) expound the normalized Hamming distance between two IVBFNs, $\tilde{\tilde{q}}_{1}=\left(\tilde{P}_{\tilde{q}_{1}}^{+}, \tilde{N}_{\tilde{\tilde{q}}_{1}}\right)=\left(\left[\tilde{P}_{\tilde{\tilde{q}}_{1}}^{L+}, \tilde{P}_{\tilde{\tilde{q}}_{1}}^{U+}\right],\left[\tilde{N}_{\tilde{\tilde{q}}_{1}}^{L-}, \tilde{N}_{\tilde{\tilde{q}}_{1}}^{U-}\right]\right)$ and $\tilde{\tilde{q}}_{2}=\left(\tilde{P}_{\tilde{\tilde{q}}_{2}}^{+}, \tilde{N}_{\tilde{\tilde{q}}_{2}}\right)=\left(\left[\tilde{P}_{\tilde{q}_{2}}^{L+}, \tilde{P}_{\tilde{\tilde{q}}_{2}}^{U+}\right]\right.$, $\left.\left[\tilde{N}_{\tilde{\tilde{q}}_{2}}^{L-}, \tilde{N}_{\tilde{\tilde{q}}_{2}}^{U-}\right]\right)$.
$d\left(\tilde{\tilde{q}}_{1}, \tilde{\tilde{q}}_{2}\right)=\frac{1}{4}\left(\left|\tilde{P}_{\tilde{\tilde{q}}_{1}}^{L+}-\tilde{P}_{\tilde{\tilde{q}}_{2}}^{L+}\right|+\left|\tilde{P}_{\tilde{\tilde{q}}_{1}}^{U+}-\tilde{P}_{\tilde{\tilde{q}}_{2}}^{U+}\right|+\left|\tilde{N}_{\tilde{\tilde{q}}_{1}}^{L-}-\tilde{N}_{\tilde{\tilde{q}}_{2}}^{L-}\right|+\left|\tilde{N}_{\tilde{\tilde{q}}_{1}}^{U-}-\tilde{N}_{\tilde{\tilde{q}}_{2}}^{U-}\right|\right)$. 


\subsection{IVBF aggregation operators}

In this part, we introduce two kinds of aggregation operators about bipolar fuzzy.

Definition 7 (Wei et al., 2018). Based on the collection of IVBFNs $\left\{\tilde{\tilde{q}}_{1}, \tilde{\tilde{q}}_{2}, \cdots, \tilde{\tilde{q}}_{i}\right\}=$ $\left\{\tilde{\tilde{q}}_{o}=\left(\tilde{P}_{\tilde{\tilde{q}}_{o}^{+}}^{+}, \tilde{N}_{\tilde{\tilde{q}}_{o}}^{\bar{q}_{o}}\right)=\left(\left[\tilde{P}_{\tilde{\tilde{q}}_{o}}^{L+}, \tilde{P}_{\tilde{q}_{o}}^{U+}\right],\left[\tilde{N}_{\tilde{\tilde{q}}_{o}}^{L-}, \tilde{N}_{\tilde{\tilde{q}}_{o}}^{U-}\right]\right) \mid o=1,2, \ldots, i\right\}$, Eq. (6) is a simple statement about the internal-valued bipolar fuzzy weighted averaging (IVBFWA) operator:

$$
\begin{aligned}
& \operatorname{IVBFWA}_{\vartheta}\left(\tilde{\tilde{q}}_{1}, \tilde{\tilde{q}}_{2}, \cdots, \tilde{\tilde{q}}_{i}\right)=\oplus_{o=1}^{i} \vartheta_{o} \tilde{\tilde{q}}_{o}= \\
& \left(\left[1-\prod_{o=1}^{i}\left(1-\tilde{P}_{\tilde{q}_{o}}^{L+}\right)^{\vartheta_{o}}, 1-\prod_{o=1}^{i}\left(1-\tilde{P}_{\tilde{q}_{o}}^{U+}\right)^{\vartheta_{o}}\right],\left[-\prod_{o=1}^{i}\left|\tilde{N}_{\tilde{q}_{o}}^{L-}\right|^{\vartheta_{o}},-\prod_{o=1}^{i}\left|\tilde{N}_{\tilde{\tilde{q}}_{o}}^{U-}\right|^{\vartheta_{o}}\right]\right),
\end{aligned}
$$

where the weighting vector is $\vartheta=\left(\vartheta_{1}, \vartheta_{2}, \cdots, \vartheta_{i}\right)^{T}\left(\vartheta_{o}>0\right.$ as well as $\left.\sum_{o=1}^{i} \vartheta_{o}=1\right)$.

Definition 8 (Wei et al., 2018). Based on the collection of IVBFNs $\left\{\tilde{\tilde{q}}_{1}, \tilde{\tilde{q}}_{2}, \cdots, \tilde{\tilde{q}}_{i}\right\}=$ $\left\{\tilde{\tilde{q}}_{o}=\left(\tilde{P}_{\tilde{q}_{o}^{+}}^{+}, \tilde{N}_{\tilde{\tilde{q}}_{o}}\right)=\left(\left[\tilde{P}_{\tilde{q}_{o}}^{L+}, \tilde{P}_{\tilde{q}_{o}}^{U+}\right],\left[\tilde{N}_{\tilde{\tilde{q}}_{o}}^{L-}, \tilde{N}_{\tilde{\tilde{q}}_{o}}^{U-}\right]\right) \mid o=1,2, \ldots, i\right\}$, Eq. (7) is a simple statement about the internal-valued bipolar fuzzy weighted geometric (IVBFWG) operator:

$$
\begin{aligned}
& \operatorname{IVBFWG}_{\vartheta}\left(\tilde{\tilde{q}}_{1}, \tilde{\tilde{q}}_{2}, \cdots, \tilde{\tilde{q}}_{i}\right)=\otimes_{o=1}^{i}\left(\tilde{\tilde{q}}_{o}\right)^{\vartheta_{o}}= \\
& \left(\left[\prod_{o=1}^{i}\left(\tilde{P}_{\tilde{\tilde{q}}_{o}}^{L+}\right)^{\vartheta_{o}}, \prod_{o=1}^{i}\left(\tilde{P}_{\tilde{\tilde{q}}_{o}}^{U+}\right)^{\vartheta_{o}}\right],\left[-1+\prod_{o=1}^{i}\left(1+\tilde{N}_{\tilde{\tilde{q}}_{o}}^{L-}\right)^{\vartheta_{o}},-1+\prod_{o=1}^{i}\left(1+\tilde{N}_{\tilde{\tilde{q}}_{o}}^{U_{-}}\right)^{\vartheta_{o}}\right]\right),
\end{aligned}
$$

where the weighting vector is $\vartheta=\left(\vartheta_{1}, \vartheta_{2}, \cdots, \vartheta_{i}\right)^{T}\left(\vartheta_{o}>0\right.$ as well as $\left.\sum_{o=1}^{i} \vartheta_{o}=1\right)$.

\section{TODIM method on the basis of Cumulative Prospect Theory}

To some extent, cumulative prospect theory (CPT) is a subversion of the traditional expected utility theory (EUT). A large number of experimental results of Tversky and Kahneman (1992) show that, in many cases, the decision maker's choice is often contrary to the results derived from the traditional EUT. Hence, through a lot of experiments and logical analysis, Tversky and Kahneman (1992) finally put forward CPT which indicates that policymakers distort probabilities, and the values are measured not in absolute quantities but in relative quantities (gains and losses). Tian et al. (2019) combined the TODIM method with CPT and proposed a method to solve the MADM problem. The specific process is as follows:

Two collections, $R=\left\{R_{1}, R_{2}, \cdots, R_{y}\right\}$ and $\Upsilon=\left\{\Upsilon_{1}, \Upsilon_{2}, \cdots, \Upsilon_{x}\right\}$, represent alternatives and attributes separately, and establish a decision matrix $Z=\left(z_{v k}\right)_{y \times x}$ with $y$ alternatives as well as $x$ attributes. Moreover, the weighting vector of attributes is $\Omega=\left(\Omega_{1}, \Omega_{2}, \cdots, \Omega_{x}\right)^{T}$ which fulfills $\Omega_{k} \geq 0$ and $\sum_{k=1}^{x} \Omega_{k}=1$. 
Step 1. Utilize the weighting function to get the revised attribute weights $\Gamma_{v g k}\left(\Omega_{k}\right)$ $(k=1,2, \cdots, x)$, just as the Eq. (8) where both $\Psi$ and $\varphi$ are as the parameters to describe the curvature of the weighting function. Furthermore, figure out the revised relative attribute weights $\Gamma_{v g k}^{*}\left(\Omega_{k}\right)(k=1,2, \cdots, x)$ in line with Eq. (9).

$$
\begin{gathered}
\Gamma_{v g k}\left(\Omega_{k}\right)=\left\{\begin{array}{l}
\left(\Omega_{k}\right)^{\Psi} /\left(\left(\Omega_{k}\right)^{\Psi}+\left(1-\Omega_{k}\right)^{\Psi}\right)^{\frac{1}{\Psi}}, \quad z_{v k} \geq z_{g k} \\
\left(\Omega_{k}\right)^{\varphi} /\left(\left(\Omega_{k}\right)^{\varphi}+\left(1-\Omega_{k}\right)^{\varphi}\right)^{\frac{1}{\varphi}}, \quad z_{v k}<z_{g k}
\end{array}\right. \\
\Gamma_{v g k}^{*}\left(\Omega_{k}\right)=\frac{\Gamma_{v g k}\left(\Omega_{k}\right)}{\max _{k}\left\{\Gamma_{v g k}\left(\Omega_{k}\right)\right\}}, v, g=1,2, \cdots, y ; k=1,2, \cdots, x .
\end{gathered}
$$

Step 2. Compare the size of $z_{v k}$ and $z_{g k}$, and on this basis calculate the predominance degree $\sigma_{k}\left(R_{v}, R_{g}\right)(v, g=1,2, \cdots, y ; k=1,2, \cdots, x)$ by using the piecewise function Eq. (10).

$$
\sigma_{k}\left(R_{v}, R_{g}\right)=\left\{\begin{array}{cl}
\frac{\Gamma_{v g k}^{*}\left(\Omega_{k}\right) \cdot\left(z_{v k}-z_{g k}\right)^{\pi}}{\sum_{k=1}^{x} \Gamma_{v g k}^{*}\left(\Omega_{k}\right)}, & \text { if } z_{v k}>z_{g k} \\
0 & \text { if } z_{v k}=z_{g k}, \\
-\varepsilon \cdot \frac{\left(\sum_{k=1}^{x} \Gamma_{v g k}^{*}\left(\Omega_{k}\right)\right) \cdot\left(z_{v k}-z_{g k}\right)^{\kappa}}{\Gamma_{v g k}^{*}\left(\Omega_{k}\right)}, & \text { if } z_{v k}<z_{g k}
\end{array}\right.
$$

where $\varepsilon, \pi$ and $\kappa$ are the parameters.

Step 3. The comprehensive predominance degree $\beta\left(R_{v}, R_{g}\right) \quad(v, g=1,2, \cdots, y)$ of alternative $R_{v}$ over alternative $R_{g}$ is calculated by Eq. (11).

$$
\beta\left(R_{v}, R_{g}\right)=\sum_{k=1}^{x} \sigma_{k}\left(R_{v}, R_{g}\right), v, g=1,2, \cdots, y .
$$

Step 4. In accordance with Eq. (12), the normative comprehensive predominance degree $\chi\left(R_{v}\right)(v=1,2, \cdots, y)$ is obtained without difficulty.

$$
\chi\left(R_{v}\right)=\frac{\sum_{g=1}^{y} \beta\left(R_{v}, R_{g}\right)-\min _{v}\left\{\sum_{g=1}^{y} \beta\left(R_{v}, R_{g}\right)\right\}}{\max _{v}\left\{\sum_{g=1}^{y} \beta\left(R_{v}, R_{g}\right)\right\}-\min _{v}\left\{\sum_{g=1}^{y} \beta\left(R_{v}, R_{g}\right)\right\}}, \quad v=1,2, \cdots, y .
$$

Step 5. Choose the optimal alternative corresponding to the maximum normative comprehensive predominance degree $\chi\left(R_{v}\right)(v=1,2, \cdots, y)$. 


\section{Interval-valued bipolar fuzzy CPT-TODIM method for MAGDM}

With the basic knowledge and theory described above, we now begin to formally describe the CPT-TODIM method under IVBF environment to be established in this paper.

There is an expert panel of $i$ people who need to evaluate $y$ alternatives from $x$ aspects. $C=\left\{C_{1}, C_{2}, \cdots, C_{i}\right\}, R=\left\{R_{1}, R_{2}, \cdots, R_{y}\right\}, \Upsilon=\left\{\Upsilon_{1}, \Upsilon_{2}, \cdots, \Upsilon_{x}\right\}$ respectively stand for the expert set, the alternative set and the attribute set. Suppose all assessment information is IVBFN, and constitute $i$ matrices $\tilde{Z}^{(o)}=\left(\tilde{z}_{v k}^{(o)}\right)_{y \times x}=\left(\left\langle\psi_{v k}^{+(o)}, \hbar_{v k}^{-(o)}\right\rangle\right)_{y \times x}=$ $\left(\left\langle\left[\psi_{v k}^{L+(o)}, \psi_{v k}^{U+(o)}\right],\left[\hbar_{v k}^{L-(o)}, \hbar_{v k}^{U-(o)}\right]\right\rangle\right)_{y \times x}\left(o_{i}=1,2, \cdots, i\right)$. At the same time, let experts' weighting vector be $\vartheta=\left(\vartheta_{1}, \vartheta_{2}, \cdots, \vartheta_{i}\right)^{T}\left(\vartheta_{o}>0, \sum_{o=1}^{i} \vartheta_{o}=1\right)$. The specific logic and thinking of the
model are as follows:

Step 1. Standardize $i$ initial matrices $\tilde{Z}^{(o)}(o=1,2, \cdots, i)$ to ensure the consistency of information, scilicet according to Eq. (13) convert the negative attribute into positive attribute. And the standardized matrix is $\hat{\tilde{Z}}^{(o)}=\left(\hat{\tilde{z}}_{v k}^{(o)}\right)_{y \times x}=\left(\left\langle\hat{\psi}_{v k}^{+(o)}, \hat{\hbar}_{v k}^{-(o)}\right\rangle\right)_{y \times x}(o=1,2, \cdots, i)$.

$$
\begin{aligned}
& \hat{\tilde{z}}_{v k}^{(o)}=\left\langle\hat{\psi}_{v k}^{+(o)}, \hat{\hbar}_{v k}^{-(o)}\right\rangle=\left\langle\left[\hat{\Psi}_{v k}^{L+(o)}, \hat{\Psi}_{v k}^{U+(o)}\right],\left[\hat{\hbar}_{v k}^{L-(o)}, \hat{\hbar}_{v k}^{U-(o)}\right]\right\rangle= \\
& \left\{\begin{array}{l}
\tilde{z}_{v k}^{(o)}=\left\langle\left[\psi_{v k}^{L+(o)}, \psi_{v k}^{U+(o)}\right],\left[\hbar_{v k}^{L-(o)}, \hbar_{v k}^{U-(o)}\right]\right\rangle, \Upsilon_{k} \text { is a positive attribute } \\
\left(\tilde{z}_{v k}^{(o)}\right)^{c}=\left\langle\begin{array}{l}
{\left[1-\psi_{v k}^{U+(o)}, 1-\psi_{v k}^{L+(o)}\right],} \\
{\left[\left|\hbar_{v k}^{U-(o)}\right|-1,\left|\hbar_{v k}^{L-(o)}\right|-1\right]}
\end{array}\right], \Upsilon_{k} \text { is a negative attribute }
\end{array}\right.
\end{aligned}
$$

Step 2. Take advantage of IVBFWA operator namely Eq. (14) to integrate assessment information contained in the $i$ matrices and form a composite matrix $\hat{Q}=\left(\hat{q}_{v k}\right)_{y \times x}$.

$$
\begin{aligned}
& \hat{q}_{v k}=\left\langle\hat{\xi}_{v k}^{+}, \hat{\ell}_{v k}^{-}\right\rangle=\left\langle\left[\hat{\xi}_{v k}^{L+}, \hat{\xi}_{v k}^{U+}\right],\left[\hat{\ell}_{v k}^{L-}, \hat{\ell}_{v k}^{U-}\right]\right\rangle=\operatorname{IVBFWA}_{\vartheta}\left(\hat{\tilde{z}}_{v k}^{(1)}, \hat{\tilde{z}}_{v k}^{(2)}, \cdots, \hat{\tilde{z}}_{v k}^{(i)}\right)=
\end{aligned}
$$

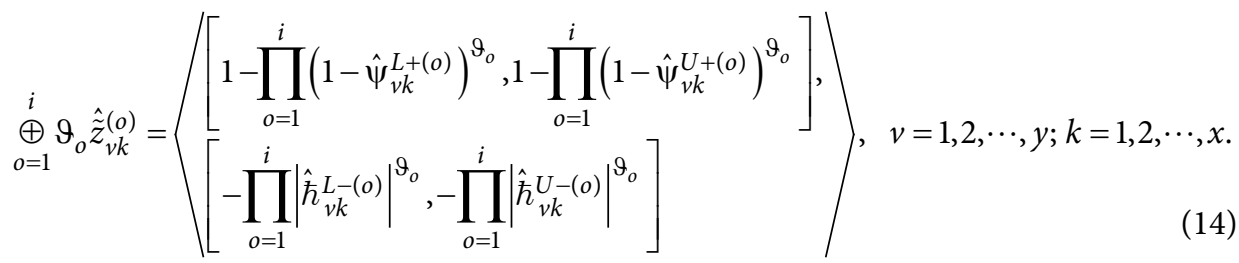

Step 3. Based on the distance Eq. (5) and the entropy weight method, obtain the basic attribute weights $\Omega_{k}\left(k=1,2, \cdots, x, \Omega_{k} \geq 0\right.$ and $\left.\sum_{k=1}^{x} \Omega_{k}=1\right)$. And the detailed procedure is shown in Eq. (15)-(16).

$$
E W_{k}=-\frac{1}{\ln y} \sum_{v=1}^{y}\left[\frac{d_{k}\left(R_{v}, R^{*}\right)}{\sum_{v=1}^{y} d_{k}\left(R_{v}, R^{*}\right)} \cdot \ln \left(\frac{d_{k}\left(R_{v}, R^{*}\right)}{\sum_{v=1}^{y} d_{k}\left(R_{v}, R^{*}\right)}\right)\right], k=1,2, \cdots, x ;
$$




$$
\Omega_{k}=\frac{1-E W_{k}}{\sum_{k=1}^{x}\left(1-E W_{k}\right)}, \quad k=1,2, \cdots, x,
$$

where $R^{*}$ is the negative point which can be depicted by Eq. (17):

$$
\begin{aligned}
& R^{*}=\left\{\hat{q}_{k}^{*} \mid k=1,2, \cdots, x\right\}=\left\{\left\langle\hat{\xi}_{k}^{+*}, \hat{\ell}_{k}^{-*}\right\rangle \mid k=1,2, \cdots, x\right\}= \\
& \left\{\left\langle\left[\hat{\xi}_{k}^{L+^{*}}, \hat{\xi}_{k}^{U+^{*}}\right],\left[\hat{\ell}_{k}^{L-*}, \hat{\ell}_{k}^{U-*}\right]\right\rangle \mid k=1,2, \cdots, x\right\}= \\
& \left\{\left\langle\left[\min _{v} \hat{\xi}_{v k}^{L+}, \min _{v} \hat{\xi}_{v k}^{U+}\right],\left[\min _{v} \hat{\ell}_{v k}^{L-}, \min _{v} \hat{\ell}_{v k}^{U-}\right]\right\rangle k=1,2, \cdots, x\right\} .
\end{aligned}
$$

Step 4. Bring in the weighting function to deal with the basic attribute weights for getting the revised attribute weights $\Gamma_{v g k}\left(\Omega_{k}\right)(k=1,2, \cdots, x)$, just as the Eq. (18) where both $\Psi$ and $\varphi$ are as the parameters to describe the curvature of the weighting function. Furthermore, figure out the revised relative attribute weights $\Gamma_{v g k}^{*}\left(\Omega_{k}\right)(k=1,2, \cdots, x)$ in line with Eq. (9).

$$
\Gamma_{v g k}\left(\Omega_{k}\right)=\left\{\begin{array}{ll}
\left(\Omega_{k}\right)^{\Psi} /\left(\left(\Omega_{k}\right)^{\Psi}+\left(1-\Omega_{k}\right)^{\Psi}\right)^{\frac{1}{\Psi}}, & \hat{q}_{v k} \geq \hat{q}_{g k} \\
\left(\Omega_{k}\right)^{\varphi} /\left(\left(\Omega_{k}\right)^{\varphi}+\left(1-\Omega_{k}\right)^{\varphi}\right)^{\frac{1}{\varphi}}, & \hat{q}_{v k}<\hat{q}_{g k}
\end{array} .\right.
$$

Step 5. Compare the size of $\hat{q}_{v k}$ and $\hat{q}_{g k}$, and on this basis calculate the predominance degree $\sigma_{k}\left(R_{v}, R_{g}\right)(v, g=1,2, \cdots, y ; k=1,2, \cdots, x)$ by using the piecewise function Eq. (19).

$$
\sigma_{k}\left(R_{v}, R_{g}\right)= \begin{cases}\frac{\Gamma_{v g k}^{*}\left(\Omega_{k}\right) \cdot\left(d_{k}\left(R_{v}, R_{g}\right)\right)^{\pi}}{\sum_{k=1}^{x} \Gamma_{v g k}^{*}\left(\Omega_{k}\right)} & , \text { if } \hat{q}_{v k}>\hat{q}_{g k} \\ -\varepsilon \cdot \frac{\left(\sum_{k=1}^{x} \Gamma_{v g k}^{*}\left(\Omega_{k}\right)\right) \cdot\left(d_{k}\left(R_{v}, R_{g}\right)\right)^{\kappa}}{\Gamma_{v g k}^{*}\left(\Omega_{k}\right)}, & \text { if } \hat{q}_{v k}=\hat{q}_{g k},\end{cases}
$$

where $\varepsilon, \pi$ as well as $\kappa$ are the parameters, and $d_{k}\left(R_{v}, R_{g}\right)$ is computed as:

$$
d_{k}\left(R_{v}, R_{g}\right)=\frac{1}{4}\left(\begin{array}{l}
\left|\hat{\xi}_{v k}^{L+}-\hat{\xi}_{g k}^{L+}\right|+\left|\hat{\xi}_{v k}^{U+}-\hat{\xi}_{g k}^{U+}\right|+ \\
\left|\hat{\ell}_{v k}^{L-}-\hat{\ell}_{g k}^{L-}\right|+\mid \hat{\ell}_{v k}^{U-}-\hat{\ell}_{g k}^{U-}
\end{array}\right), \quad v, g=1,2, \cdots, y ; k=1,2, \cdots, x .
$$

The calculated outcomes of any two alternatives under attribute $\Upsilon_{k}$ can be expressed in terms of matrix $\sigma_{k}(k=1,2, \cdots, x)$ : 


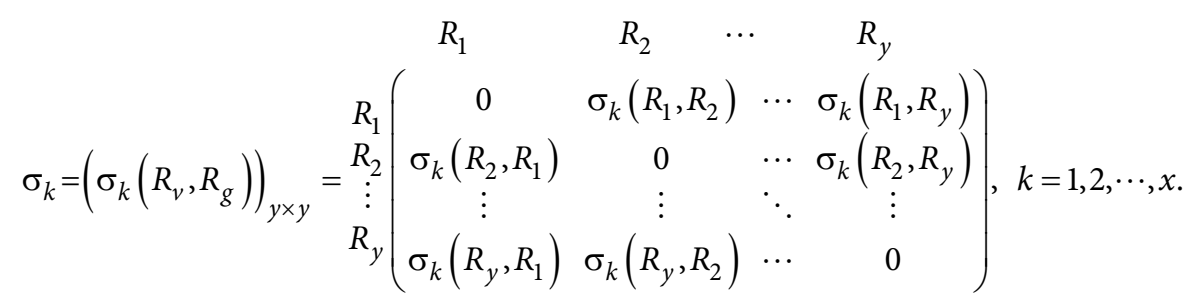

Step 6. Add the $x$ matrices obtained in the previous step in accordance with corresponding positions to acquire the comprehensive predominance matrix $\beta$. And each element of the matrix $\beta$ is the comprehensive predominance degree $\beta\left(R_{v}, R_{g}\right)(v, g=1,2, \cdots, y)$ of alternative $R_{v}$ over alternative $R_{g}$ calculated by Eq. (11).

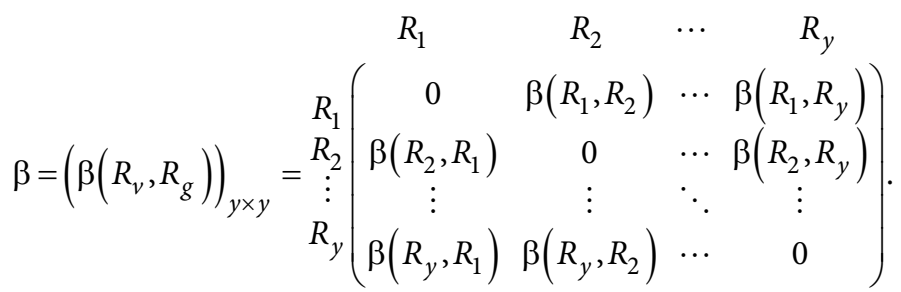

Step 7. In accordance with Eq. (12), the normative comprehensive predominance degree (NCPD) $\chi\left(R_{v}\right)(v=1,2, \cdots, y)$ is obtained without difficulty. The optimal alternative corresponds to the maximum normative comprehensive predominance degree.

\section{Numerical example}

Industrial control system is the brain and central nerve of important national infrastructure including electric power, transportation, energy, aviation and aerospace, etc. More than $80 \%$ of the key infrastructure related to people's livelihood needs to rely on ICS to realize automatic operation. With the development of technology, ICS is facing more new threats like virus, Trojan, hacker and so on. At present, the scale level of ICS security manufacturers is uneven. And many ICS security manufacturers provide security products are aimed at protecting part or several parts, such as the industrial firewall, industrial gate and so on. The distinction between the security of ICS and traditional information security is that ICS requires a more comprehensive protection rather than the impregnability of a particular point of protection. There needs an integrated safety product are which can run through the whole life cycle of production to ensure comprehensive safety protection for ICS. Therefore, it is very important for industrial enterprises to evaluate the comprehensive capability of ICS security suppliers from different perspectives to choose the right partner finally. Now, an enterprise needs to select one of five ICS security suppliers $R_{v}(v=1,2,3,4,5)$ for strategic cooperation. In addition, the three decision makers $C_{o}(o=1,2,3)$, whose weighting vector is $\vartheta=\left(\vartheta_{1}, \vartheta_{2}, \vartheta_{3}\right)^{T}=(0.32,0.29,0.39)^{T}$ decided to evaluate the comprehensive capabilities of these five suppliers from the following four aspects, including: (1) $\Upsilon_{1}$ is the safety prevention and control capacity; (2) $\Upsilon_{2}$ is the product fit; (3) $\Upsilon_{3}$ is the abnormal response time; (4) $\Upsilon_{4}$ 
is future development capability of the enterprise. It should be noted that attribute $\Upsilon_{3}$ is a cost attribute that follows the principle of smaller is better, while other attributes follow the principle of larger is better. The initial evaluation results are shown in Table 1 to Table 3.

Table 1. The IVBF matrix $\tilde{Z}^{(1)}$

\begin{tabular}{|c|c|c|c|c|}
\hline & $\Upsilon_{1}$ & $\Upsilon_{2}$ & $\Upsilon_{3}$ & $\Upsilon_{4}$ \\
\hline$R_{1}$ & $\left\langle\begin{array}{l}{[0.65,0.86],} \\
{[-0.12,-0.10]}\end{array}\right\rangle$ & $\left\langle\begin{array}{l}{[0.65,0.74],} \\
{[-0.26,-0.18]}\end{array}\right\rangle$ & $\left\langle\begin{array}{l}{[0.34,0.52],} \\
{[-0.56,-0.47]}\end{array}\right\rangle$ & $\left\langle\begin{array}{l}{\left[\begin{array}{l}{[0.72,0.88]} \\
{[-0.15,-0.09]}\end{array}\right\rangle}\end{array}\right.$ \\
\hline$R_{2}$ & $\left\langle\begin{array}{l}{[0.58,0.74],} \\
{[-0.34,-0.25]}\end{array}\right\rangle$ & $\left\langle\begin{array}{l}{\left[\begin{array}{l}{[0.64,0.77]} \\
{[-0.31,-0.21]}\end{array}\right\rangle}\end{array}\right.$ & $\left\langle\left\langle\left\langle\begin{array}{l}{[0.26,0.49]} \\
{[-0.67,-0.54]}\end{array}\right\rangle\right.\right.$ & 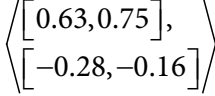 \\
\hline$R_{3}$ & $\left\langle\begin{array}{l}{[0.32,0.48],} \\
{[-0.54,-0.42]}\end{array}\right\rangle$ & $\left\langle\begin{array}{l}{[0.68,0.82],} \\
{[-0.24,-0.15]}\end{array}\right\rangle$ & $\left\langle\begin{array}{l}{[0.48,0.57],} \\
{[-0.49,-0.38]}\end{array}\right\rangle$ & $\begin{array}{l}{\left[\begin{array}{l}{[0.34,0.52],} \\
{[-0.63,-0.51]}\end{array}\right.}\end{array}$ \\
\hline$R_{4}$ & $\left\langle\begin{array}{l}{[0.63,0.84],} \\
{[-0.20,-0.13]}\end{array}\right\rangle$ & 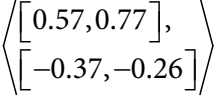 & $\left\langle\begin{array}{l}{[0.15,0.29],} \\
{[-0.88,-0.83]}\end{array}\right\rangle$ & $\left\langle\begin{array}{l}{[0.57,0.71]} \\
{[-0.42,-0.35]}\end{array}\right\rangle$ \\
\hline$R_{5}$ & $\left\langle\begin{array}{l}{[0.49,0.67],} \\
{[-0.39,-0.28]}\end{array}\right\rangle$ & $\left\langle\begin{array}{l}{[0.61,0.72],} \\
{[-0.27,-0.19]}\end{array}\right\rangle$ & $\left\langle\begin{array}{l}{[0.35,0.52],} \\
{[-0.65,-0.57]}\end{array}\right\rangle$ & $\left\langle\begin{array}{l}{[0.69,0.82]} \\
{[-0.24,-0.12]}\end{array}\right\rangle$ \\
\hline
\end{tabular}

Table 2. The IVBF matrix $\tilde{Z}^{(2)}$

\begin{tabular}{|c|c|c|c|c|}
\hline & $\Upsilon_{1}$ & $\Upsilon_{2}$ & $\Upsilon_{3}$ & $\Upsilon_{4}$ \\
\hline$R_{1}$ & $\left\langle\begin{array}{l}{[0.52,0.69],} \\
{[-0.44,-0.34]}\end{array}\right\rangle$ & $\left\langle\begin{array}{l}{[0.56,0.68],} \\
{[-0.41,-0.32]}\end{array}\right\rangle$ & $\left\langle\begin{array}{l}{[0.12,0.23]} \\
{[-0.92,-0.86]}\end{array}\right\rangle$ & $\left\langle\begin{array}{l}{[0.82,0.91]} \\
{[-0.11,-0.04]}\end{array}\right\rangle$ \\
\hline$R_{2}$ & $\left\langle\begin{array}{l}{[0.66,0.83],} \\
{[-0.22,-0.16]}\end{array}\right\rangle$ & $\left\langle\begin{array}{l}{[0.43,0.62],} \\
{[-0.44,-0.31]}\end{array}\right\rangle$ & $\left\langle\begin{array}{l}{[0.21,0.29],} \\
{[-0.87,-0.82]}\end{array}\right)$ & $\left\langle\begin{array}{l}{\left[\begin{array}{l}0.66,0.78] \\
{[-0.25,-0.13]}\end{array}\right.}\end{array}\right\rangle$ \\
\hline$R_{3}$ & $\left\langle\begin{array}{l}{[0.41,0.59],} \\
{[-0.52,-0.43]}\end{array}\right\rangle$ & $\left\langle\begin{array}{l}{[0.72,0.80],} \\
{[-0.16,-0.12]}\end{array}\right\rangle$ & $\left\langle\begin{array}{l}{[0.35,0.43],} \\
{[-0.56,-0.44]}\end{array}\right)$ & $\left\langle\begin{array}{l}{[0.49,0.62],} \\
{[-0.46,-0.37]}\end{array}\right\rangle$ \\
\hline$R_{4}$ & $\left\langle\begin{array}{l}{[0.55,0.67],} \\
{[-0.42,-0.33]}\end{array}\right\rangle$ & $\left\langle\begin{array}{l}{[0.52,0.66],} \\
{[-0.42,-0.35]}\end{array}\right\rangle$ & $\left\langle\begin{array}{l}{[0.26,0.38]} \\
{[-0.68,-0.59]}\end{array}\right\rangle$ & $\left\langle\begin{array}{l}{[0.74,0.83]} \\
{[-0.17,-0.13]}\end{array}\right\rangle$ \\
\hline$R_{5}$ & $\left\langle\begin{array}{l}{[0.37,0.51],} \\
{[-0.65,-0.49]}\end{array}\right\rangle$ & $\left\langle\begin{array}{l}{[0.64,0.71],} \\
{[-0.28,-0.15]}\end{array}\right\rangle$ & $\left\langle\begin{array}{l}{[0.28,0.40]} \\
{[-0.62,-0.54]}\end{array}\right\rangle$ & $\left\langle\begin{array}{l}{[0.72,0.86],} \\
{[-0.13,-0.08]}\end{array}\right\rangle$ \\
\hline
\end{tabular}


Table 3. The IVBF matrix $\tilde{Z}^{(3)}$

\begin{tabular}{|c|c|c|c|c|}
\hline & $\Upsilon_{1}$ & $\Upsilon_{2}$ & $\Upsilon_{3}$ & $\Upsilon_{4}$ \\
\hline$R_{1}$ & $\left\langle\begin{array}{l}{[0.72,0.90],} \\
{[-0.11,-0.06]}\end{array}\right\rangle$ & $\left\langle\begin{array}{l}{[0.63,0.75],} \\
{[-0.37,-0.28]}\end{array}\right\rangle$ & $\left\langle\begin{array}{l}{[0.23,0.31],} \\
{[-0.73,-0.65]}\end{array}\right\rangle$ & $\left\langle\begin{array}{l}{[0.65,0.73],} \\
{[-0.31,-0.24]}\end{array}\right\rangle$ \\
\hline$R_{2}$ & $\left\langle\begin{array}{l}{[0.65,0.75],} \\
{[-0.26,-0.17]}\end{array}\right\rangle$ & $\left\langle\begin{array}{l}{[0.58,0.69],} \\
{[-0.46,-0.33]}\end{array}\right\rangle$ & $\left\langle\begin{array}{l}{[0.29,0.38],} \\
{[-0.65,-0.54]}\end{array}\right\rangle$ & $\left\langle\begin{array}{l}{[0.73,0.88],} \\
{[-0.18,-0.12]}\end{array}\right)$ \\
\hline$R_{3}$ & $\left\langle\begin{array}{l}{[0.62,0.73],} \\
{[-0.31,-0.22]}\end{array}\right\rangle$ & $\left\langle\begin{array}{l}{[0.75,0.81],} \\
{[-0.14,-0.11]}\end{array}\right\rangle$ & $\left\langle\begin{array}{l}{[0.42,0.56],} \\
{[-0.45,-0.36]}\end{array}\right\rangle$ & $\left\langle\begin{array}{l}{[0.53,0.62],} \\
{[-0.43,-0.34]}\end{array}\right\rangle$ \\
\hline$R_{4}$ & $\left\langle\begin{array}{l}{[0.63,0.77],} \\
{[-0.29,-0.19]}\end{array}\right\rangle$ & $\left\langle\begin{array}{l}{[0.59,0.73],} \\
{[-0.42,-0.31]}\end{array}\right\rangle$ & $\left\langle\begin{array}{l}{[0.32,0.42],} \\
{[-0.62,-0.52]}\end{array}\right\rangle$ & $\left\langle\begin{array}{l}{[0.69,0.76],} \\
{[-0.26,-0.15]}\end{array}\right\rangle$ \\
\hline$R_{5}$ & $\left\langle\begin{array}{l}{[0.48,0.60],} \\
{[-0.52,-0.46]}\end{array}\right\rangle$ & $\left\langle\begin{array}{l}{[0.66,0.75],} \\
{[-0.24,-0.16]}\end{array}\right\rangle$ & $\left\langle\begin{array}{l}{[0.40,0.52],} \\
{[-0.41,-0.32]}\end{array}\right\rangle$ & $\left\langle\begin{array}{l}{[0.62,0.73],} \\
{[-0.33,-0.21]}\end{array}\right\rangle$ \\
\hline
\end{tabular}

The calculation steps and corresponding results of using the proposed interval-valued bipolar fuzzy TODIM method based on CPT (IVBF-CPT-TODIM) to solve the problem are as follows:

Step 1. Standardize three initial matrices $\tilde{Z}^{(o)}(o=1,2,3)$ independently given by decision makers according to Eq. (13).

Step 2. Take advantage of Eq. (14) to integrate assessment information contained in the three matrices and form a composite matrix $\hat{Q}=\left(\hat{q}_{v k}\right)_{5 \times 4}$, shown in Table 4 .

Table 4. The IVBF group matrix $\hat{Q}$

\begin{tabular}{|c|c|c|c|c|}
\hline & $\Upsilon_{1}$ & $\Upsilon_{2}$ & $\Upsilon_{3}$ & $\Upsilon_{4}$ \\
\hline$R_{1}$ & $\left\langle\begin{array}{l}{[0.6484,0.8454],} \\
{[-0.1691,-0.1168]}\end{array}\right\rangle$ & $\left\langle\begin{array}{l}{[0.6178,0.7281],} \\
{[-0.3405,-0.2527]}\end{array}\right\rangle$ & $\left\langle\begin{array}{l}{[0.6645,0.7842],} \\
{[-0.3064,-0.2218]}\end{array}\right\rangle$ & $\left\langle\begin{array}{l}{[0.7313,0.8485],} \\
{[-0.1820,-0.1043]}\end{array}\right)$ \\
\hline$R_{2}$ & $\left\langle\begin{array}{l}{[0.6321,0.7736],} \\
{[-0.2699,-0.1890]}\end{array}\right\rangle$ & $\left\langle\begin{array}{l}{[0.5632,0.7011]} \\
{[-0.4002,-0.2804]}\end{array}\right\rangle$ & $\left\langle\begin{array}{l}{[0.6189,0.7450]} \\
{[-0.3504,-0.2577]}\end{array}\right\rangle$ & $\left\langle\begin{array}{l}{[0.6807,0.8191]} \\
{[-0.2281,-0.1347]}\end{array}\right\rangle$ \\
\hline$R_{3}$ & $\left\langle\begin{array}{l}{[0.4799,0.6241],} \\
{[-0.4302,-0.3286]}\end{array}\right\rangle$ & $\left\langle\begin{array}{l}{[0.7204,0.8105],} \\
{[-0.1729,-0.1246]}\end{array}\right\rangle$ & $\left\langle\begin{array}{l}{\left[\begin{array}{l}0.4784,0.5842] \\
{[-0.6095,-0.5032]}\end{array}\right\rangle}\end{array}\right.$ & $\left\langle\begin{array}{l}{[0.4635,0.5905]} \\
{[-0.4955,-0.3967]}\end{array}\right)$ \\
\hline$R_{4}$ & $\left\langle\begin{array}{l}{[0.6084,0.7726],} \\
{[-0.2867,-0.1975]}\end{array}\right\rangle$ & $\left\langle\begin{array}{l}{[0.5642,0.7258],} \\
{[-0.4033,-0.3035]}\end{array}\right\rangle$ & $\left\langle\begin{array}{l}{[0.6376,0.7636],} \\
{[-0.3290,-0.2500]}\end{array}\right\rangle$ & $\left(\begin{array}{l}{[0.6729,0.7693]} \\
{[-0.2680,-0.1887]}\end{array}\right)$ \\
\hline$R_{5}$ & $\left\langle\begin{array}{l}{[0.4536,0.6011],} \\
{[-0.5060,-0.3997]}\end{array}\right\rangle$ & 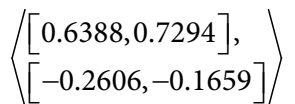 & $\left.\begin{array}{l}\langle[0.5181,0.6544], \\
{[-0.5243,-0.4394]}\end{array}\right\rangle$ & $\left\langle\begin{array}{l}{\left[\begin{array}{l}{[0.6741,0.8040]} \\
{[-0.2275,-0.1327]}\end{array}\right.}\end{array}\right)$ \\
\hline
\end{tabular}


Step 3. Based on the distance Eq. (5) and the entropy weight method (Eq. (15)-(17)), obtain the basic attribute weights $\Omega_{k}\left(k=1,2,3,4, \Omega_{k} \geq 0\right.$ and $\left.\sum_{k=1}^{4} \Omega_{k}=1\right)$.

$$
\Omega=\left(\Omega_{1}, \Omega_{2}, \Omega_{3}, \Omega_{4}\right)^{T}=(0.2548,0.3462,0.2296,0.1694)^{T}
$$

Step 4. The Eqs (18) and (9) give us a way to get the revised relative attribute weights $\Gamma_{v g k}^{*}\left(\Omega_{k}\right)(v, g=1,2,3,4,5 ; k=1,2,3,4)$, just as Table 5 . And the values of parameters $\Psi=0.61$ and $\varphi=0.69$ in Eq. (18) are derived from the experimental proof of Tversky and Kahneman (1992).

Table 5. The revised relative weights

\begin{tabular}{|c|c|c|c|c|c|c|c|c|c|}
\hline & $\Upsilon_{1}$ & $\Upsilon_{2}$ & $\Upsilon_{3}$ & $\Upsilon_{4}$ & $\Upsilon_{1}$ & $\Upsilon_{2}$ & $\Upsilon_{3}$ & $\Upsilon_{4}$ & $\Upsilon_{1}$ \\
\hline$\Gamma_{12}^{*}$ & 0.8566 & 1 & 0.8139 & 0.7024 & $\Gamma_{34}^{*}$ & 0.8665 & 1 & 0.8143 & 0.6799 \\
\hline$\Gamma_{13}^{*}$ & 0.8206 & 1 & 0.7797 & 0.6728 & $\Gamma_{35}^{*}$ & 0.8566 & 1 & 0.8143 & 0.6799 \\
\hline$\Gamma_{14}^{*}$ & 0.8566 & 1 & 0.8139 & 0.7024 & $\Gamma_{41}^{*}$ & 0.8301 & 1 & 0.7800 & 0.6513 \\
\hline$\Gamma_{15}^{*}$ & 0.8206 & 1 & 0.7797 & 0.6728 & $\Gamma_{42}^{*}$ & 0.8301 & 1 & 0.7797 & 0.6513 \\
\hline$\Gamma_{21}^{*}$ & 0.8301 & 1 & 0.7800 & 0.6513 & $\Gamma_{43}^{*}$ & 0.8206 & 1 & 0.7797 & 0.6728 \\
\hline$\Gamma_{23}^{*}$ & 0.8206 & 1 & 0.7797 & 0.6728 & $\Gamma_{45}^{*}$ & 0.8206 & 1 & 0.7797 & 0.6513 \\
\hline$\Gamma_{24}^{*}$ & 0.8566 & 1 & 0.8143 & 0.7024 & $\Gamma_{51}^{*}$ & 0.8665 & 1 & 0.8143 & 0.6799 \\
\hline$\Gamma_{25}^{*}$ & 0.8206 & 1 & 0.7797 & 0.6728 & $\Gamma_{52}^{*}$ & 0.8665 & 1 & 0.8143 & 0.6799 \\
\hline$\Gamma_{31}^{*}$ & 0.8665 & 1 & 0.8143 & 0.6799 & $\Gamma_{53}^{*}$ & 0.8301 & 1 & 0.7797 & 0.6728 \\
\hline$\Gamma_{32}^{*}$ & 0.8665 & 1 & 0.8143 & 0.6799 & $\Gamma_{54}^{*}$ & 0.8665 & 1 & 0.8143 & 0.7024 \\
\hline
\end{tabular}

Step 5. Utilize Eq. (20) to derive the distinction $d_{k}\left(R_{v}, R_{g}\right)$ in each two alternatives under all of attributes (shown in Table 6) and obtain the predominance degree matrix $\sigma_{k}$ $(k=1,2,3,4)$. The values of parameters $\varepsilon=0.88, \pi=0.88$ and $\kappa=2.25$ in Eq. (19) are derived from the experimental proof of Tversky and Kahneman (1992).

Table 6. Distance between each two alternatives

\begin{tabular}{|c|c|c|c|c|c|c|c|c|c|}
\hline & $\Upsilon_{1}$ & $\Upsilon_{2}$ & $\Upsilon_{3}$ & $\Upsilon_{4}$ & & $\Upsilon_{1}$ & $\Upsilon_{2}$ & $\Upsilon_{3}$ & $\Upsilon_{4}$ \\
\hline$d\left(R_{1}, R_{2}\right)$ & 0.0653 & 0.0423 & 0.0412 & 0.0391 & $d\left(R_{2}, R_{4}\right)$ & 0.0125 & 0.0130 & 0.0166 & 0.0379 \\
\hline$d\left(R_{1}, R_{3}\right)$ & 0.2157 & 0.1202 & 0.2426 & 0.2829 & $d\left(R_{2}, R_{5}\right)$ & 0.1994 & 0.0895 & 0.1367 & 0.0060 \\
\hline$d\left(R_{1}, R_{4}\right)$ & 0.0778 & 0.0424 & 0.0246 & 0.0770 & $d\left(R_{3}, R_{4}\right)$ & 0.1379 & 0.1625 & 0.2181 & 0.2059 \\
\hline$d\left(R_{1}, R_{5}\right)$ & 0.2647 & 0.0472 & 0.1779 & 0.0439 & $d\left(R_{3}, R_{5}\right)$ & 0.0490 & 0.0729 & 0.0647 & 0.2390 \\
\hline$d\left(R_{2}, R_{3}\right)$ & 0.1504 & 0.1624 & 0.2015 & 0.2438 & $d\left(R_{4}, R_{5}\right)$ & 0.1869 & 0.0896 & 0.1534 & 0.0331 \\
\hline
\end{tabular}




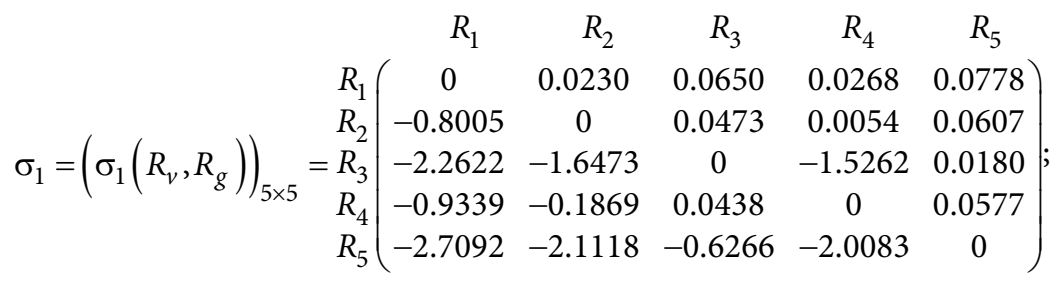

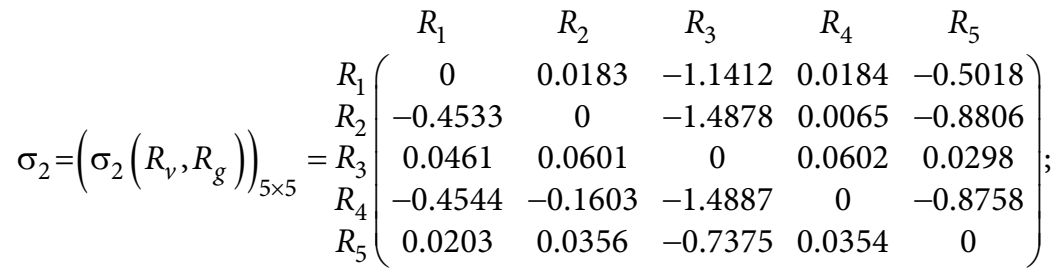

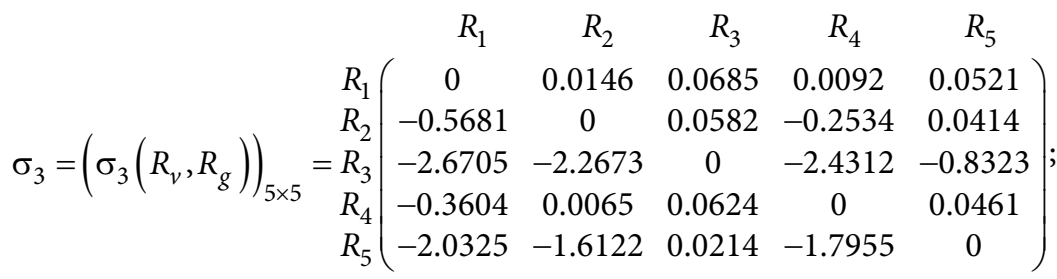

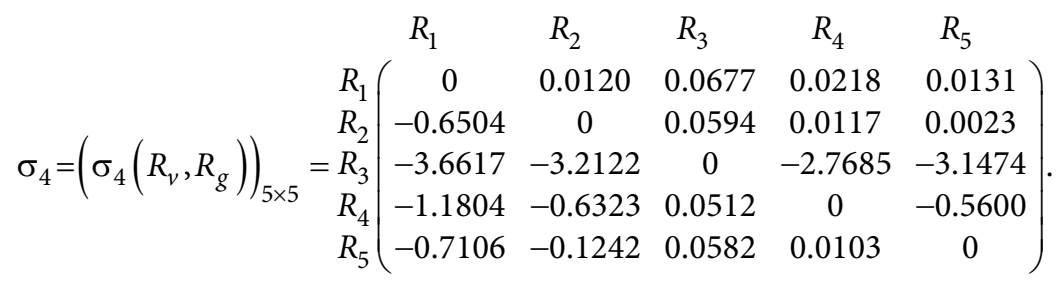

Step 6. Acquire the comprehensive predominance matrix $\beta$ in accordance with Eq. (11).

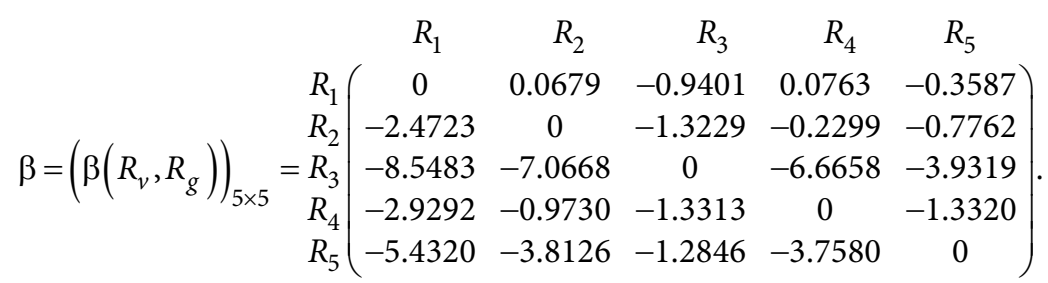

Step 7. In accordance with Eq. (12), the normative comprehensive predominance degree (NCPD) $\chi\left(R_{v}\right)(v=1,2,3,4,5)$ is obtained without difficulty. The optimal alternative is $R_{1}$.

$$
\begin{aligned}
& \chi\left(R_{1}\right)=1, \chi\left(R_{2}\right)=0.8545, \chi\left(R_{v}\right)=0, \chi\left(R_{4}\right)=0.7841, \chi\left(R_{5}\right)=0.4759, \\
& R_{1}>R_{2}>R_{4}>R_{5}>R_{3} .
\end{aligned}
$$




\section{Comprehensive analysis}

\subsection{Sensitivity analysis}

The five parameters $(\Psi, \varphi, \varepsilon, \pi, \kappa)$ involved in this model undoubtedly have an impact on the final results, so we attempt to analyze the influence of these parameters. Firstly, we roughly discuss these parameters' meaning. Parameters $\Psi$ and $\varphi$ are evaluated between 0 and 1 . The closer the value is to 1 , the more distorted the initial weight is. Parameters $\varepsilon, \pi$, and $\kappa$ reflect the decision makers' attitudes toward gains, losses, and risks. $\pi$ is no more than $\kappa$ that indicates decision makers are more sensitive to losses. $\varepsilon$ determines the risk type of decision maker, and $\varepsilon$ for risk averter is greater than 1.

\subsubsection{The sensitivity analysis of weight parameters}

In this section, we intend to discuss the two parameters ( $\Psi$ and $\varphi$ ) of the weighting function. As can be seen from the data in Table 7, when the first parameter $\Psi$ changes, the difference between diverse alternatives is gradually narrowing, while the single change of parameter $\varphi$ causes completely opposite effect. However, the ordering of alternatives is always unaltered.

Table 7. The outcomes of parameters $\Psi$ and $\varphi$ varying separately

\begin{tabular}{|c|c|c|c|c|c|}
\hline \multicolumn{3}{|c|}{$\varphi=0.69$} & \multicolumn{3}{|c|}{$\Psi=0.61$} \\
\hline$\Psi$ & NCPD & The order & $\varphi$ & NCPD & The order \\
\hline 0.1 & $\begin{array}{l}\chi\left(R_{1}\right)=1 \\
\chi\left(R_{2}\right)=0.8313 \\
\chi\left(R_{3}\right)=0 \\
\chi\left(R_{4}\right)=0.7383 \\
\chi\left(R_{5}\right)=0.4860\end{array}$ & $R_{1}>R_{2}>R_{4}>R_{5}>R_{3}$ & 0.1 & $\begin{array}{l}\chi\left(R_{1}\right)=1 \\
\chi\left(R_{2}\right)=0.8618 \\
\chi\left(R_{3}\right)=0 \\
\chi\left(R_{4}\right)=0.8613 \\
\chi\left(R_{5}\right)=0.3760\end{array}$ & $R_{1}>R_{2}>R_{4}>R_{5}>R_{3}$ \\
\hline 0.3 & $\begin{array}{l}\chi\left(R_{1}\right)=1 \\
\chi\left(R_{2}\right)=0.8403 \\
\chi\left(R_{3}\right)=0 \\
\chi\left(R_{4}\right)=0.7584 \\
\chi\left(R_{5}\right)=0.4740\end{array}$ & $R_{1}>R_{2}>R_{4}>R_{5}>R_{3}$ & 0.3 & $\begin{array}{l}\chi\left(R_{1}\right)=1 \\
\chi\left(R_{2}\right)=0.8509 \\
\chi\left(R_{3}\right)=0 \\
\chi\left(R_{4}\right)=0.7991 \\
\chi\left(R_{5}\right)=0.4305\end{array}$ & $R_{1}>R_{2}>R_{4}>R_{5}>R_{3}$ \\
\hline 0.5 & $\begin{array}{l}\chi\left(R_{1}\right)=1 \\
\chi\left(R_{2}\right)=0.8507 \\
\chi\left(R_{3}\right)=0 \\
\chi\left(R_{4}\right)=0.7781 \\
\chi\left(R_{5}\right)=0.4737\end{array}$ & $R_{1}>R_{2}>R_{4}>R_{5}>R_{3}$ & 0.5 & $\begin{array}{l}\chi\left(R_{1}\right)=1 \\
\chi\left(R_{2}\right)=0.8504 \\
\chi\left(R_{3}\right)=0 \\
\chi\left(R_{4}\right)=0.7843 \\
\chi\left(R_{5}\right)=0.4566\end{array}$ & $\begin{array}{l}R_{1}>R_{2}>R_{4} \\
>R_{5}>R_{3}\end{array}$ \\
\hline 0.7 & $\begin{array}{l}\chi\left(R_{1}\right)=1 \\
\chi\left(R_{2}\right)=0.8567 \\
\chi\left(R_{3}\right)=0 \\
\chi\left(R_{4}\right)=0.7872 \\
\chi\left(R_{5}\right)=0.4779\end{array}$ & $R_{1}>R_{2}>R_{4}>R_{5}>R_{3}$ & 0.7 & $\begin{array}{l}\chi\left(R_{1}\right)=1 \\
\chi\left(R_{2}\right)=0.8547 \\
\chi\left(R_{3}\right)=0 \\
\chi\left(R_{4}\right)=0.7842 \\
\chi\left(R_{5}\right)=0.4769\end{array}$ & $R_{1}>R_{2}>R_{4}>R_{5}>R_{3}$ \\
\hline
\end{tabular}


End of Table 7

\begin{tabular}{|c|l|l|l|l|l|}
\hline \multicolumn{2}{|c|}{$\varphi=0.69$} & \multicolumn{3}{c|}{$\Psi=0.61$} \\
\hline$\Psi$ & \multicolumn{1}{|c|}{ NCPD } & \multicolumn{1}{|c|}{ The order } & $\varphi$ & \multicolumn{1}{c|}{ NCPD } & \multicolumn{1}{|c|}{ The order } \\
\hline \multirow{5}{*}{0.9} & & & $\chi\left(R_{1}\right)=1$ & \\
& $\chi\left(R_{1}\right)=1$ & & $\chi\left(R_{2}\right)=0.8612$ & \\
& $\chi\left(R_{2}\right)=0.8597$ & & & \\
& $\chi\left(R_{3}\right)=0$ & $R_{1}>R_{2}>R_{4}>R_{5}>R_{3}$ & 0.9 & $\chi\left(R_{3}\right)=0$ & $R_{1}>R_{2}>R_{4}>R_{5}>R_{3}$ \\
& $\chi\left(R_{4}\right)=0.7903$ & & & $\chi\left(R_{4}\right)=0.7885$ & \\
& $\chi\left(R_{5}\right)=0.4820$ & & & $\chi\left(R_{5}\right)=0.4960$ & \\
\hline
\end{tabular}

\subsubsection{The sensitivity analysis of value parameters}

In this section, we intend to discuss the three parameters $(\varepsilon, \pi$, and $\kappa)$ of the value function. When the three parameters of the value function are changed separately, we can get the data in Table 8. From these data, we can see that the order of alternatives remains constant, but the relative relationship between alternatives has slight changed. This indicates that the parameters' influence on the overall stability of the proposed method is not great, although affecting the final value of $\operatorname{NCPD} \chi\left(R_{v}\right)(v=1,2,3,4,5)$.

When two parameters $\pi$ and $\kappa$ in the value function change at the same time, we draw the graph shown in Figure 1. From Figure 1, we can see that the relationship between alternatives doesn't change with the transformation of the two parameters, which indicates that the stability of this method is good. However, the gradual increase of parameter $\pi$ significantly shortens the difference between alternatives, while the increase of parameter $\kappa$ has relatively little impact.

\subsection{Comparative analysis}

Through the above example, we successfully solve the problem of selecting the optimal security supplier for industrial control system by making use of the new model proposed in this paper, but the reliability of this model still needs to be further tested and proved. Hence, we choose two operators (Wei et al., 2018), IVBFWA operator, IVBFWG operator, for comparative analysis, and the results are as follows Table 9.

From Table 10, we can clearly realize that alternative $R_{1}$ is the optimal alternative. IVBFWA operators and IVBFWG operators evaluate all of alternatives from the perspective of the whole or the individual respectively. Compared with them, the special method proposed in this paper has a more in-depth consideration of the factors that affect the decision result. On the one hand, in terms of attribute weights, the entropy weight method is adopted in this model. Replacing subjective weight with objective weight can reduce uncertainty and improve the stability of results. At the same time, before calculating the relative weights, the initial objective weights are processed through the weight function in CPT, which is based on the influence of decision-makers' opinions on the attribute weights in reality. On the other hand, the model described in this paper is proposed on the basis of CPT and the traditional TODIM method. The fusion of these two theories makes the psychological description of decision makers more real, and the effect is also more real and effective than the traditional TODIM method. Most importantly, IVBFN, as a new way to describe uncertainty and fuzziness, is of great significance for developing MAGDM problems in fuzzy environments. 


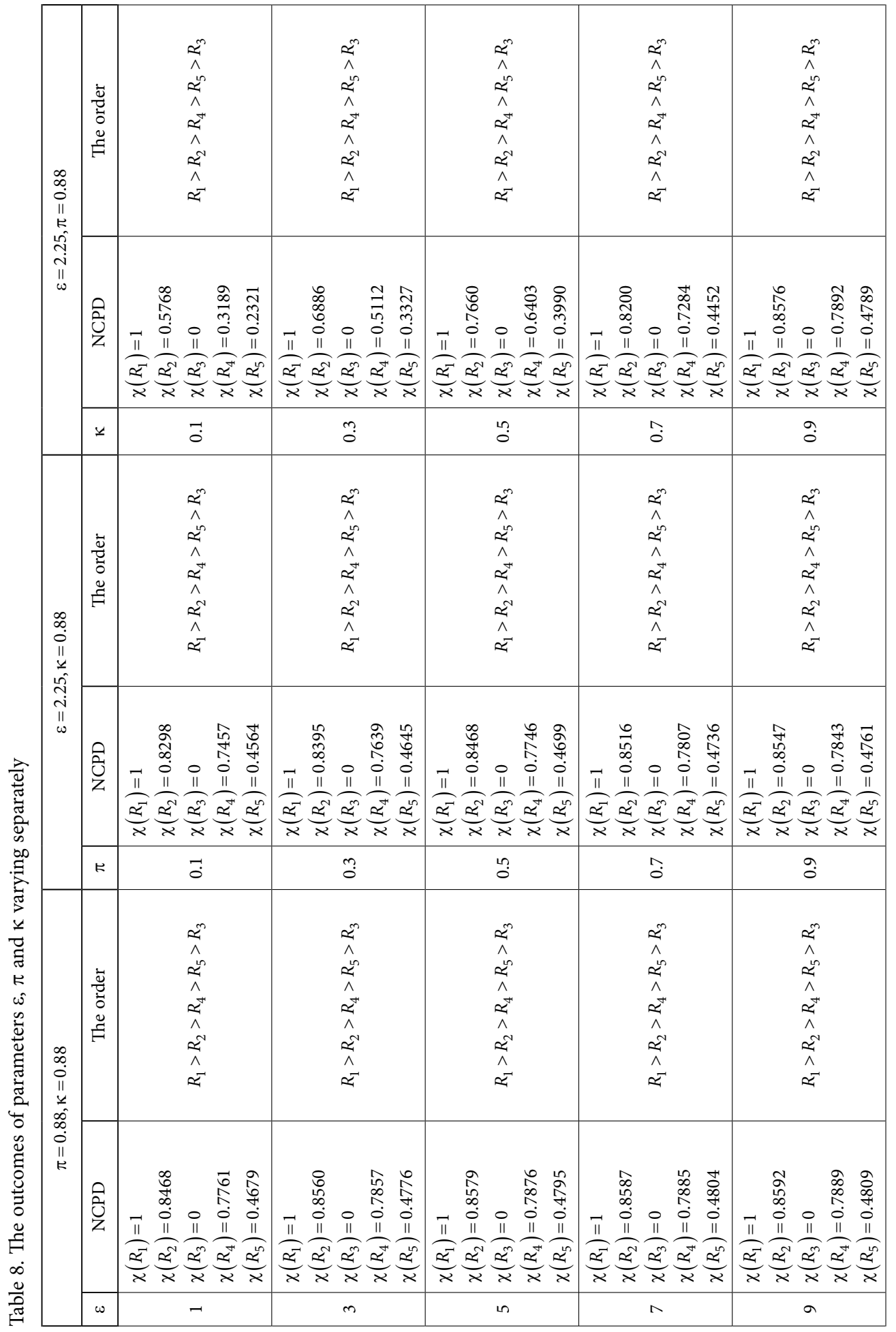




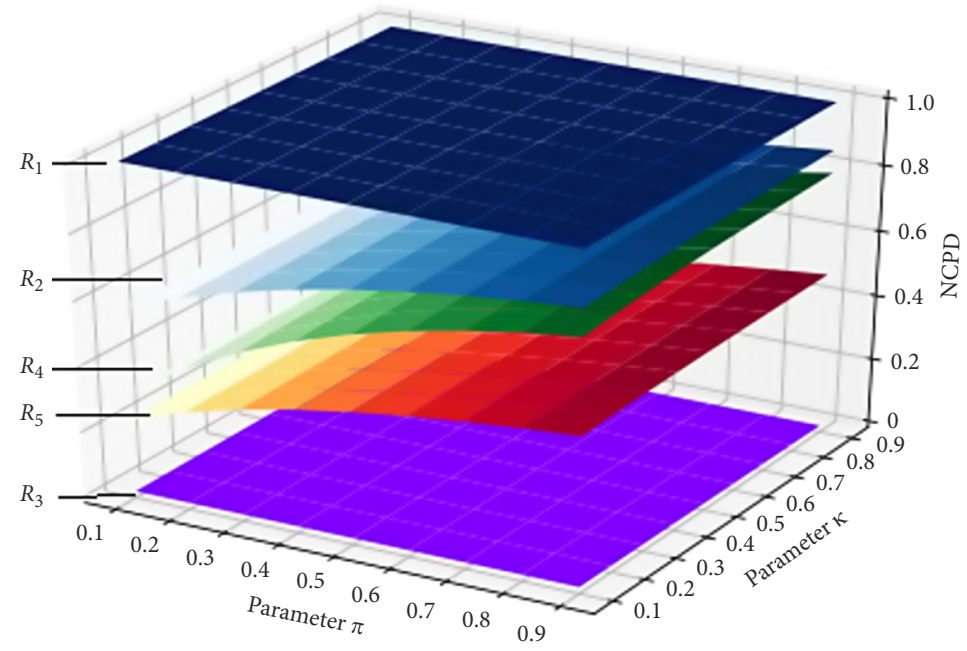

Figure 1 . The outcomes of parameters $\pi$ and $\kappa$ varying simultaneously

Table 9. The outcomes of IVBFWA and IVBFWG operators

\begin{tabular}{|c|c|c|c|c|}
\hline & IVBFWA & Score value & IVBFWG & Score value \\
\hline$R_{1}$ & $\left\langle\begin{array}{l}{[0.6579,0.7977],} \\
{[-0.2501,-0.1734]}\end{array}\right\rangle$ & 0.7580 & $\left\langle\begin{array}{l}{[0.6544,0.7895],} \\
{[-0.2661,-0.1884]}\end{array}\right\rangle$ & 0.7474 \\
\hline$R_{2}$ & $\left\langle\begin{array}{l}{[0.6157,0.7534],} \\
{[-0.3192,-0.2197]}\end{array}\right\rangle$ & 0.7076 & $\left\langle\begin{array}{l}{[0.6120,0.7485],} \\
{[-0.3297,-0.2291]}\end{array}\right\rangle$ & 0.7004 \\
\hline$R_{3}$ & $\left\langle\begin{array}{l}{[0.5780,0.6921],} \\
{[-0.3481,-0.2674]}\end{array}\right\rangle$ & 0.6636 & $\left\langle\begin{array}{l}{[0.5487,0.6666],} \\
{[-0.4177,-0.3255]}\end{array}\right\rangle$ & 0.6180 \\
\hline$R_{4}$ & $\left\langle\begin{array}{l}{[0.6128,0.7546],} \\
{[-0.3292,-0.2401]}\end{array}\right\rangle$ & 0.6995 & $\left\langle\begin{array}{l}{[0.6095,0.7535],} \\
{[-0.3359,-0.2463]}\end{array}\right\rangle$ & 0.6952 \\
\hline$R_{5}$ & $\left\langle\begin{array}{l}{[0.5786,0.7008],} \\
{[-0.3541,-0.2500]}\end{array}\right\rangle$ & 0.6688 & $\left\langle\begin{array}{l}{[0.5631,0.6885],} \\
{[-0.3926,-0.2952]}\end{array}\right\rangle$ & 0.6409 \\
\hline The order & \multicolumn{2}{|c|}{$R_{1}>R_{2}>R_{4}>R_{5}>R_{3}$} & \multicolumn{2}{|c|}{$R_{1}>R_{2}>R_{4}>R_{5}>R_{3}$} \\
\hline
\end{tabular}

Table 10. Comparison of the final orders of different methods

\begin{tabular}{|l|c|}
\hline \multicolumn{1}{|c|}{ Method } & The order \\
\hline IVBFWA & $R_{1}>R_{2}>R_{4}>R_{5}>R_{3}$ \\
\hline IVBFWG & $R_{1}>R_{2}>R_{4}>R_{5}>R_{3}$ \\
\hline IVBF-CPT-TODIM & $R_{1}>R_{2}>R_{4}>R_{5}>R_{3}$ \\
\hline
\end{tabular}




\section{Conclusions}

The application of Internet in industry has broken the relatively closed manufacturing environment of traditional industry and provided the possibility for intelligent manufacturing. Using information technology to reform the traditional industrial enterprises has been the inevitable trend of the development of industrial enterprises. At the same time, it also means Industrial enterprises face new safety problems. Because industry is more closely linked to national economy and people's livelihood, the safety of ICS is paid more attention by the state and the public. In this paper, a new TODIM method based on CPT for MAGDM is proposed in IVBF environment, which successfully solves the problem of selecting security suppliers for ICS. The IVBF-CPT-TODIM method not only takes into full account the attitude of decision maker towards gain and loss in comparison between alternatives, but also has a good improvement in terms of attribute weights, that is, it uses the entropy weight method to obtain objective weights and reprocesses them according to weight function. In order to fully discuss and confirm the IVBF-CPT-TODIM method, the knowledge of IVBFS is reviewed in the part 2 of this paper. The CPT and TODIM methods are then briefly summarized in the third part of the article. The fourth part is the focus of this paper, which elaborates on the logical structure of IVBF-CPT-TODIM method. What's more, in the last two sections, we apply this newly constructed model to the security of ICS, and verify the acceptability of this method by comprehensive analysis.

Our team always makes it our mission to build scientific and rational decision methods to address MADM or MAGDM issues. In the future, we will seek the application of CPTTODIM method in more fields, and also explore advanced theories and algorithms in various fields.

\section{References}

Akram, M., Shumaiza, \& Arshad, M. (2020). Bipolar fuzzy TOPSIS and bipolar fuzzy ELECTRE-I methods to diagnosis. Computational \& Applied Mathematics, 39, 7.

https://doi.org/10.1007/s40314-019-0980-8

Arya, V., \& Kumar, S. (2020a). A new picture fuzzy information measure based on shannon entropy with applications in opinion polls using extended VIKOR-TODIM approach. Computational \& Applied Mathematics, 39, 197. https://doi.org/10.1007/s40314-020-01228-1

Arya, V., \& Kumar, S. (2020b). A novel TODIM-VIKOR approach based on entropy and Jensen-Tsalli divergence measure for picture fuzzy sets in a decision-making problem. International Journal of Intelligent Systems, 35, 2140-2180. https://doi.org/10.1002/int.22289

Ashofteh, P. S., Golfam, P., \& Loaiciga, H. A. (2020). Evaluation of river water transfer alternatives with the TODIM multi-criteria decision making method. Water Resources Management, 34, 4847-4863. https://doi.org/10.1007/s11269-020-02694-2

Atanassov, K. T. (1986). Intuitionistic fuzzy sets. Fuzzy Sets and Systems, 20, 87-96. https://doi.org/10.1016/S0165-0114(86)80034-3

Gomes, L., \& Rangel, L. A. D. (2009). An application of the TODIM method to the multicriteria rental evaluation of residential properties. European Journal of Operational Research, 193, 204-211. https://doi.org/10.1016/j.ejor.2007.10.046 
Guo, J., Yin, J. L., Zhang, L., Lin, Z. F., \& Li, X. (2020). Extended TODIM method for CCUS storage site selection under probabilistic hesitant fuzzy environment. Applied Soft Computing, 93, 106381. https://doi.org/10.1016/j.asoc.2020.106381

He, S. F., Pan, X. H., \& Wang, Y. M. (2021). A shadowed set-based TODIM method and its application to large-scale group decision making. Information Sciences, 544, 135-154. https://doi.org/10.1016/j.ins.2020.07.028

He, T., Wei, G., Lu, J., Wu, J., Wei, C., \& Guo, Y. (2020a). A novel EDAS based method for multiple attribute group decision making with pythagorean 2-tuple linguistic information. Technological and Economic Development of Economy, 26, 1125-1138. https://doi.org/10.3846/tede.2020.12733

He, T., Zhang, S., Wei, G., Wang, R., Wu, J., \& Wei, C. (2020b). CODAS method for 2-tuple linguistic pythagorean fuzzy multiple attribute group decision making and its application to financial management performance assessment. Technological and Economic Development of Economy, 26, 920-932. https://doi.org/10.3846/tede.2020.11970

Jana, C., Pal, M., \& Wang, J. Q. (2020). Bipolar fuzzy Dombi prioritized aggregation operators in multiple attribute decision making. Soft Computing, 24, 3631-3646.

https://doi.org/10.1007/s00500-019-04130-z

Keshavarz Ghorabaee, M., Zavadskas, E. K., Olfat, L., \& Turskis, Z. (2015). Multi-criteria inventory classification using a new method of Evaluation Based on Distance from Average Solution (EDAS). Informatica, 26, 435-451. https://doi.org/10.15388/Informatica.2015.57

Keshavarz Ghorabaee, M., Zavadskas, E. K., Turskis, Z., \& Antucheviciene, J. (2016). A new combinative distance-based assessment (CODAS) method for multi-criteria decision-making. Economic Computation and Economic Cybernetics Studies and Research, 50, 25-44.

Liu, L., Wu, J., Wei, G., Wei, C., Wang, J., \& Wei, Y. (2020). Entropy-based GLDS method for social capital selection of a PPP project with q-rung orthopair fuzzy information. Entropy, 22(4), 414. https://doi.org/10.3390/e22040414

Lu, J. P., He, T. T., Wei, G. W., Wu, J., \& Wei, C. (2020). Cumulative prospect theory: performance evaluation of government purchases of home-based elderly-care services using the Pythagorean 2-tuple linguistic TODIM method. International Journal of Environmental Research and Public Health, 17(6), 1939. https://doi.org/10.3390/ijerph17061939

Mishra, A. R., Rani, P., Pardasani, K. R., Mardani, A., Stevic, Z., \& Pamucar, D. (2020). A novel entropy and divergence measures with multi-criteria service quality assessment using interval-valued intuitionistic fuzzy TODIM method. Soft Computing, 24, 11641-11661. https://doi.org/10.1007/s00500-019-04627-7

Opricovic, S., \& Tzeng, G. H. (2004). Compromise solution by MCDM methods: A comparative analysis of VIKOR and TOPSIS. European Journal of Operational Research, 156, 445-455. https://doi.org/10.1016/S0377-2217(03)00020-1

Paelinck, J. H. P. (1978). Qualiflex - flexible multiple-criteria method. Economics Letters, 1, 193-197. https://doi.org/10.1016/0165-1765(78)90023-X

Pamucar, D., \& Cirovic, G. (2015). The selection of transport and handling resources in logistics centers using Multi-Attributive Border Approximation area Comparison (MABAC). Expert Systems with Applications, 42, 3016-3028. https://doi.org/10.1016/j.eswa.2014.11.057

Shannon, C. E. (1948). A mathematical theory of communication. Bell System Technical Journal, 27, 379-423. https://doi.org/10.1002/j.1538-7305.1948.tb01338.x

Tehrim, S. T., \& Riaz, M. (2020). An interval-valued bipolar fuzzy linguistic VIKOR method using connection numbers of SPA theory and its application to decision support system. Journal of Intelligent \& Fuzzy Systems, 39, 3931-3948. https://doi.org/10.3233/JIFS-200038

Tian, X., Niu, M., Zhang, W., Li, L., \& Herrera-Viedma, E. (2021). A novel TODIM based on Prospect theory to select green supplier with q-rung orthopair fuzzy set. Technological and Economic Development of Economy, 27(2), 284-310. https://doi.org/10.3846/tede.2020.12736 
Tian, X. L., Niu, M. L., Ma, J. S., \& Xu, Z. S. (2020). A novel TODIM with probabilistic hesitant fuzzy information and its application in green supplier selection. Complexity, 2020, 2540798. https://doi.org/10.1155/2020/2540798

Tian, X. L., Xu, Z. S., \& Gu, J. (2019). An extended TODIM based on cumulative prospect theory and its application in venture capital. Informatica, 30, 413-429. https://doi.org/10.15388/Informatica.2019.212

Tversky, A., \& Kahneman, D. (1992). Advances in prospect theory: cumulative representation of uncertainty. Journal of Risk and Uncertainty, 5, 297-323. https://doi.org/10.1007/BF00122574

Wang, S., Wei, G., Wu, J., Wei, C., \& Guo, Y. (2021). Model for selection of hospital constructions with probabilistic linguistic GRP method. Journal of Intelligent \& Fuzzy Systems, 40, 1245-1259. https://doi.org/10.3233/JIFS-201543

Wei, G., Lei, F., Lin, R., Wang, R., Wei, Y., Wu, J., \& Wei, C. (2020). Algorithms for probabilistic uncertain linguistic multiple attribute group decision making based on the GRA and CRITIC method: application to location planning of electric vehicle charging stations. Economic Research-Ekonomska Istraživanja, 33(1), 828-846. https://doi.org/10.1080/1331677X.2020.1734851

Wei, G. W., Wei, C., \& Gao, H. (2018). Multiple attribute decision making with interval-valued bipolar fuzzy information and their application to emerging technology commercialization evaluation. IEEE Access, 6, 60930-60955. https://doi.org/10.1109/ACCESS.2018.2875261

Wu, X. L., \& Liao, H. C. (2019). A consensus-based probabilistic linguistic gained and lost dominance score method. European Journal of Operational Research, 272, 1017-1027. https://doi.org/10.1016/j.ejor.2018.07.044

Xiao, L., Zhang, S., Wei, G., Wu, J., Wei, C., Guo, Y., \& Wei, Y. (2020). Green supplier selection in steel industry with intuitionistic fuzzy Taxonomy method. Journal of Intelligent \& Fuzzy Systems, 39, 7247-7258. https://doi.org/10.3233/JIFS-200709

Xu, D. S., Wei, X. L., Ding, H., \& Bin, H. Q. (2020). A new method based on PROMETHEE and TODIM for multi-attribute decision-making with single-valued neutrosophic sets. Mathematics, 8 , 1816. https://doi.org/10.3390/math8101816

Yazdani, M., Zarate, P., Zavadskas, E. K., \& Turskis, Z. (2018). A combined compromise solution (CoCoSo) method for multi-criteria decision-making problems. Management Decision, 57, 2501-2519. https://doi.org/10.1108/MD-05-2017-0458

Zadeh, L. A. (1965). Fuzzy sets. Information and Control, 8, 338-356. https://doi.org/10.1016/S0019-9958(65)90241-X

Zhang, W. R. (1996). NPN fuzzy sets and NPN qualitative algebra: A computational framework for bipolar cognitive modeling and multiagent decision analysis. Ieee Transactions on Systems Man and Cybernetics Part B-Cybernetics, 26, 561-574. https://doi.org/10.1109/3477.517031

Zhao, M., Wei, G., Wei, C., \& Wu, J. (2021a). Improved TODIM method for intuitionistic fuzzy MAGDM based on cumulative prospect theory and its application on stock investment selection. International Journal of Machine Learning and Cybernetics, 12, 891-901.

https://doi.org/10.1007/s13042-020-01208-1

Zhao, M., Wei, G., Wei, C., Wu, J., \& Wei, Y. (2021b). Extended CPT-TODIM method for intervalvalued intuitionistic fuzzy MAGDM and its application to urban ecological risk assessment. Journal of Intelligent \& Fuzzy Systems, 40(3), 4091-4106. https://doi.org/10.3233/JIFS-200534

Zhao, M., Wei, G., Wu, J., Guo, Y., \& Wei, C. (2021c). TODIM method for multiple attribute group decision making based on cumulative prospect theory with 2-tuple linguistic neutrosophic sets. International Journal of Intelligent Systems, 36, 1199-1222. https://doi.org/10.1002/int.22338 